\title{
Der Kommentar als Modellfall sozialhistorischer Differenzierung
}

\author{
Lateinisch-deutsche Sprachlogiken in der Überlieferung \\ des Granum sinapis
}

\section{Nach der Sozialgeschichte - nach der Kulturgeschichte? Der Kommentar als Modellfall sozialhistorischer Differenzierung}

Das vielfach konstatierte `Ende`sozialgeschichtlich orientierter Fragestellungen in der Literaturwissenschaft ${ }^{1}$ scheint aktuell demjenigen des einst >neuen Forschungsparadigmas `Kultur $\mathrm{zu}$ korrespondieren, welches den gesellschaftshistorischen Ansatz - unter veränderten Prämissen - in ein aufgrund des interdisziplinären Zugriffs notwendig allgemeiner gefasstes Modell überführt hatte. ${ }^{2}$ Auch wenn dieses auf eine Loslösung vom engeren, mit Funktionszuweisungen operierenden Frageinteresse sozialhistorischer Konzepte zielte, blieb das Phänomen der »Überblendung des Konzepts der `Gesellschaft durch das der `Kultur « ${ }^{3}$

1 Vgl. (mit weiterführenden Angaben) Martin Huber, Gerhard Lauer (Hg.): Nach der Sozialgeschichte. Konzepte für eine Literaturwissenschaft zwischen historischer Anthropologie, Kulturgeschichte und Medientheorie. Tübingen 2000. Siehe in spezifisch germanistischer Perspektive Martina Wagner-Egelhaaf: Literaturtheorie als Theorie der Gesellschaft. In: Promotionskolleg >Literaturtheorie als Theorie der Gesellschaft` (Hg.): Literatur. Macht. Gesellschaft. Neue Beiträge zur theoretischen Modellierung des Verhältnisses von Literatur und Gesellschaft. Heidelberg 2015, S. 17-38.

2 Vgl. aus germanistisch-mediävistischer Sicht den Überblick bei Ursula Peters: Text und Kontext. Die Mittelalterphilologie zwischen Gesellschaftsgeschichte und Kulturanthropologie. In: Ursula Peters: Von der Sozialgeschichte zur Kulturwissenschaft. Aufsätze 1973-2000. Hg. von Susanne Bürkle, Lorenz Deutsch, Timo Reuvekamp-Felber. Tübingen, Basel 2004, S. 301-334. Eine Auswahl kulturwissenschaftlich orientierter Einzelstudien bietet Jan-Dirk Müller: Mediävistische Kulturwissenschaft. Ausgewählte Studien. Berlin 2010.

3 Ursula Peters: Die Rückkehr der >Gesellschaft` in die Kulturwissenschaft. Zur gesellschaftsgeschichtlichen Neuorientierung der Mittelalterphilologie. In: Scientia Poetica 22 (2018), S. 1-52. Peters verweist in diesem Zusammenhang auf das durch den ıneuen` Ansatz gleichfalls ungelöst gebliebene >Text-Kontext-Problem`. Vgl. Dominic Büker: Intertextualität und Distinktion. Grundzüge einer kultursoziologischen Text-Kontext-Theorie. In: Promotionskolleg >Literaturtheorie als

Julia Frick, Zürich 
seinerseits von nachhaltigem Irritationspotential: ${ }^{4}$ Die Fokussierung auf abstraktere Konstruktionen von gesellschaftsgeschichtlicher Relevanz (wie Mentalitäts-, Ideen-, Diskurs-, Medien-, Wissensgeschichte etc.) brachte mit einer zunehmenden Spezialisierung im Bereich der einzelnen Forschungsansätze gerade keine oder allenfalls nur eine punktuell zu beobachtende - Präzisierung der infrage stehenden Relation von Text und Kultur, ${ }^{5}$ sondern vielmehr eine signifikante Verengung des Blickwinkels, indem sie den literarischen Text auf jeweils einen, aus der Breite kulturhistorischer Modellbildungen separierten theoretischen Aspekt verpflichtete - ein Vorgang, der sich, zumal aus historischer Perspektive, mit dem Verdacht der >bloßen ^Applikation eines vorgegebenen Sinnhorizonts auseinandersetzen muss. ${ }^{6}$ Umso gravierender erscheint dieses Phänomen angesichts der evidenten Komplexisierung des sich ausdifferenzierenden Feldes der Kulturwissenschaften, insofern mit dessen Aufsplitterung eine gewisse >Entgrenzung « der Forschungsdisziplin einhergeht, die die traditionellen Kategorien von >Text und >Kontext diskurs übergeordneten literaturwissenschaftlichen Operationalisierbarkeit entzieht. ${ }^{7}$ Dass damit eine »trennscharfe, >sozialgeschichtliche` Perspektive ${ }^{8}$ nicht erfasst, ja mit der Pluralisierung in geistes-, mentalitäts-, medialitäts-, wissensgeschichtliche etc. Kategorien gar nicht erst anvisiert ist, liegt auf der Hand.

Theorie der Gesellschaft` (Hg.): Neue Beiträge zur theoretischen Modellierung des Verhältnisses von Literatur und Gesellschaft. Heidelberg 2015, S. 41-78.

4 Vgl. hierzu Claus-Michael Ort: \Sozialgeschichteくals Herausforderung der Literaturwissenschaft. Zur Aktualität eines Projekts. In: Martin Huber, Gerhard Lauer (Hg.): Nach der Sozialgeschichte. Konzepte für eine Literaturwissenschaft zwischen historischer Anthropologie, Kulturgeschichte und Medientheorie. Tübingen 2000, S. 113-128.

5 Zum Problemfeld `Text als Kultur und der spezifisch `kulturellen Poetik (cultural poetics) vgl. im Kontext des New Historicism einschlägig Catherine Gallgher, Stephen Greenblatt: Practicing New Historicism. Chicago 2000. Siehe dazu auch Moritz Baßler (Hg.): New Historicism. Literaturgeschichte als Poetik der Kultur. Mit Beiträgen von Stephen Greenblatt, Louis Monrose u. a. Frankfurt a.M. 1995; Bachmann-Medick (Hg.): Kultur als Text. Die anthropologische Wende in der Literaturwissenschaft. Frankfurt a.M. 1996.

6 Vgl. dazu die einzelnen Artikel im Band von Christiane Ackermann, Michael Egerding (Hg.): Literatur und Kulturtheorien in der Germanistischen Mediävistik. Ein Handbuch. Berlin 2015, sowie die Rezension von Rüdiger Schnell: Kulturtheorien und Lektürepraxis in der Germanistischen Mediävistik. In: ZfdA 145 (2016), S. 421-458. Schnell insistiert insbesondere auf dem Monitum, dass sich die Germanistische Mediävistik als »Anhäufung von Forschungsansätzen [präsentiert], die aufgrund ihrer enormen Komplexitätssteigerung immer weiter auseinanderdriften « (ebd., S. 457). Zur >dilemmatischen` Beziehung der Literatur- und Kulturwissenschaft vgl. auch Walter Haug: Literaturwissenschaft als Kulturwissenschaft? In: DVjs 73 (1999), S. 69-93.

$7 \mathrm{Zu}$ diesem Problemfeld vgl. eingehend die Einleitung des Bandes.

8 Ort: `Sozialgeschichte` als Herausforderung der Literaturwissenschaft (s. Anm. 4), S. 116. 
Die germanistisch-mediävistische Forschung hat immer wieder mit Vehemenz auf die kulturwissenschaftliche Tradition des Faches, die eine adäquate Verortung der Texte »in weitgespannte[n] kulturgeschichtliche[n] Kontexten« notwendig mache, hingewiesen. ${ }^{9}$ Insbesondere durch die Stilisierung der Kulturwissenschaft zur »universale[n] Textwissenschaft ${ }^{10}$ schien die Spezifizität literarischer Ausdrucksformen, wie sie sich in Texten manifestieren, in einem kulturhistorischen Kontinuum unterzugehen, das sich aus den unterschiedlichsten Repräsentationsformen gleichermaßen lesbarer >Texte` konstituierte. Auch der Versuch, den Verlust an Differenzierung durch eine gewissermaßen charakteristisch mediävistische Ausprägung der Kulturgeschichte - forciert durch die Forderungen der $>$ New Philology ${ }^{11}$ - als Medien- bzw. Überlieferungsgeschichte zu kompensieren, ${ }^{12}$ offenbart in der Verschiebung des Blickwinkels auf die Manuskriptkultur symptomatische >Leerstellen`. Denn das überlieferte Material lässt aufgrund der zum Teil nicht unerheblichen zeitlichen Distanz zur Entstehung der darin fixierten Texte deren sozialen und kulturellen Hintergrund allenfalls erahnen und spiegelt damit einen differenten, auf einer anderen Ebene anzusiedelnden Status »historische[r] Realität «, ${ }^{13}$ nämlich eine rezeptionsorientierte Perspektive aus der Überlieferung rekonstruierbarer Gebrauchs- und Funktionszusammenhänge der erhaltenen Codices. ${ }^{14}$ Neuere kulturgeschichtliche Ansätze in der Germanistischen Mediävistik hingegen arbeiten mit dezidiert offeneren Deutungshorizonten,

9 Peters: Text und Kontext (s. Anm. 2), S. 307. Vgl. dazu auch Jan-Dirk Müller: Der Widerspenstigen Zähmung. Anmerkungen zu einer mediävistischen Kulturwissenschaft. In: Martin Huber, Gerhard Lauer (Hg.): Nach der Sozialgeschichte. Konzepte für eine Literaturwissenschaft zwischen historischer Anthropologie, Kulturgeschichte und Medientheorie. Tübingen 2000, S. 461-481, bes. S. 461.

10 Haug: Literaturwissenschaft als Kulturwissenschaft (s. Anm. 6), S. 82.

11 Vgl. die Revision des Forschungsfeldes in Markus Stock, A. E. Christa Canitz (Hg.): Rethinking Philology. Twenty-Five Years after The New Philology. Ottawa 2015, darin bes. den Beitrag von Stephen G. Nichols: Dynamic Reading of Medieval Manuscripts, S. 19-57, der die Überlegungen aus der seinerzeit wirkmächtigen Speculum-Ausgabe reflektiert: Stephen G. Nichols: Introduction. Philology in a Manuscript Culture. In: Speculum 65 (1990), S. 1-10.

12 Vgl. (mit Diskussion des Forschungsstandes) die stheoretischen und kulturhistorischen Vorbemerkungen bei Jürgen Wolf: Buch und Text. Literatur- und kulturhistorische Untersuchungen zur volkssprachigen Schriftlichkeit im 12. und 13. Jahrhundert. Tübingen 2008.

13 Wolf: Buch und Text (s. Anm. 12), S. 54.

14 Damit verschiebt sich der Blickwinkel von den sozial- und kulturhistorischen Entstehungsbedingungen der Texte auf den Gebrauchscharakter der Manuskripte selbst. Vgl. exemplarisch Felix Heinzer: Über das Wort hinaus lesen? Der Psalter als Erstlesebuch und die Folgen für das mittelalterliche Verhältnis zum Text. In: Wolfgang Haubrichs, Eckart Conrad Lutz (Hg.): Text und Text in lateinischer und volkssprachiger Überlieferung des Mittelalters. Freiburger Kolloquium 2004. Berlin 2006, S. 147-168. 
indem sie die Aspekte des `Kulturellen` auf die Sphäre von imaginären Bedeutungsstrukturen verschieben, die in den literarischen Texten als Produkten jeweils konkreter historischer Konstellationen beobachtbar werden. ${ }^{15}$ Gleichwohl ist auch hier eine gewisse Prägnanz »kulturspezifische[r] Interessen und Impulse ${ }^{16}{ }^{16} \mathrm{z}$ gunsten eines stärker mentalitätsgeschichtlichen, abstrakteren Modells einer simaginären (Wissens-)Ordnung ‘ der historischen Kultur zurückgestellt, ${ }^{17}$ das zwar als Anschlusskommunikation an »das - inzwischen aufgegebene - Projekt einer Sozialgeschichte der Literatur « konzipiert ist, ${ }^{18}$ das gleichwohl ohne dezidierte Anbindung an sozialhistorische Fragen auskommt. ${ }^{19}$

Angesichts dieser Sachlage dokumentieren die von den Herausgebern des vorliegenden Bandes zurecht kritisch hinterfragten, ins Unspezifische tendierenden Kontextualisierungsbemühungen offensichtlich eine Art Kompensationsmodell scheinbar obsolet gewordener Fragehorizonte. ${ }^{20}$ Das gilt umso mehr, als einige neuere »Überlegungen zur Verbindung von kulturwissenschaftlicher Literatur- und Gesellschaftstheorie, der straditionellen ihrer Vermittlungsproblematik « durchaus, ${ }^{21}$ insbesondere im Hinblick auf die textanalytische Realisierung, auf `klassische` Paradigmen sozialgeschichtlicher Forschung rekurrieren. ${ }^{22}$ Diese Ansätze reflektieren eine Defizienz des kulturgeschichtlichen Ansatzes, der die sozialhistorische Bedingtheit der Literatur - und das gilt in besonderem Maße für die mittelalterliche Literatur in der Volkssprache nur unzureichend erfasst. Ursula Peters votiert in ihrem Plädoyer insofern ganz folgerichtig »für eine detailhistorisch basierte gesellschaftsgeschichtlich orientierte Mittelalterphilologie«, um unter einem veränderten Blickwinkel »neue Antworten auf salte literarhistorische Fragen « herauszuarbeiten. ${ }^{23}$

15 Vgl. Jan-Dirk Müller: Höfische Kompromisse. Acht Kapitel zur höfischen Epik. Tübingen 2007.

16 Ebd., S. 9.

17 Vgl. Müllers Ausführungen in der zur Textanalyse hinführenden Einleitung, ebd., S. 6-41, sowie die kritische Diskussion des Konzepts bei Hartmut Bleumer: Oblique Lektüren. Ein Versuch zu: Jan-Dirk Müller, Höfische Kompromisse. Acht Kapitel zur höfischen Epik. Niemeyer, Tübingen 2007. In: ZfdPh 131 (2012), S. 103-115.

18 Müller: Höfische Kompromisse (s. Anm. 15), S. 40.

19 Vgl. dazu die differenzierte Darstellung in der Einleitung des Bandes (bes. S. 7f.).

20 Vgl. Ursula Peters: Literaturgeschichte als Mentalitätsgeschichte? Überlegungen zur Problematik einer neueren Forschungsrichtung. In: Ursula Peters: Von der Sozialgeschichte zur Kulturwissenschaft. Aufsätze 1973-2000. Hg. von Susanne Bürkle, Lorenz Deutsch, Timo Reuvekamp-Felber. Tübingen, Basel 2004, S. 75-106, bes. S. 79.

21 Peters: Die Rückkehr der `Gesellschaft $\triangleleft$ in die Kulturwissenschaft (s. Anm. 3), S. 5 f.

22 Ebd., S. 29. Peters analysiert die Zugriffe der postcolonial studies, der Ökokritik und Ökonomie auf ihre Valenz im Hinblick auf gesellschaftsgeschichtliche Fragestellungen.

23 Peters: Die Rückkehr der >Gesellschaft in die Kulturwissenschaft (s. Anm. 3), S. 49 u. 52. 
Als eine solche Antwort versteht sich der folgende Beitrag. Ziel ist es zu eruieren, inwiefern sich der Problematik kultur- und sozialgeschichtlicher Referentialisierung methodisch kontrolliert und historisch adäquat begegnen lässt, um die Differenzqualität realhistorischer Konstanten und kultureller Konstellationen zu erfassen, auf die literarische Texte in der ihnen je eigenen Art der Konstruktion symbolischer Ordnung begegnen. ${ }^{24}$ Als exemplarischer Modellfall dient dabei der Funktionstypus des Kommentars. ${ }^{25}$

Als Medium der Wissenssicherung und Wissensvermittlung repräsentiert der Kommentar eine ıSammlung` von Sinngebungsprozeduren, ${ }^{26}$ die das jeweils kommentierte Einzelwerk in universale epistemische Dimensionen und damit in ein Symbolsystem von thematischer Markiertheit integriert. ${ }^{27}$ Die solchermaßen durchaus hierarchisch gegliederte Ordnung des vorliegenden Materials generiert einen >Wissensraum , der als Referenzgröße für die Identitätsbildung eines Kollektivs wirkt, in dessen Umfeld sie zu verorten ist. Das ist insofern von entscheidender Bedeutung, weil nur diejenigen Werke als kommentierungsbedürftig erscheinen, die im Rahmen kultureller Distinktionen kanonische bzw. $>$ klassische`Geltung erlangt haben ${ }^{28}$ und denen insofern eine gewisse gesellschaftliche Verbindlichkeit - sei es in rechtlich-fundierender Hinsicht, sei es im bildungsgeschichtlichen Kontext - eignet. ${ }^{29}$ Was natürlich auch umgekehrt gilt,

24 Zu möglichen Zugängen zu Text-Kontext-Relationen vgl. in literaturwissenschaftlicher Perspektive Christian Kiening: Zwischen Körper und Schrift. Texte vor dem Zeitalter der Literatur. Frankfurt a.M. 2003, bes. S. 8-28.

25 Vgl. grundlegend Glenn W. Most (Hg.): Commentaries - Kommentare. Göttingen 1999. In historischer Perspektive siehe Frank Bezner: Vela veritatis. Hermeneutik, Wissen und Sprache in der Intellectual History des 12. Jahrhunderts. Leiden, Köln 2005.

26 Zum Sammeln in systematischer Hinsicht vgl. Aleida Assmann, Monika Gomille, Gabriele Rippl (Hg.): Sammler - Bibliophile - Exzentriker. Tübingen 1998. Vgl. auch die theoretische Grundlegung in Jan Assmann, Burkhard Bladigow (Hg.): Text und Kommentar. Archäologie der literarischen Kommunikation IV. München 1995, sowie grundlegend Jan Assmann: Das kulturelle Gedächtnis. Schrift, Erinnerung und politische Identität in frühen Hochkulturen. München ${ }^{8} 2018$.

27 Vgl. Walter Haug: Der Kommentar und sein Subjekt. Grundpositionen exegetischer Kommentierung in Spätantike und Mittelalter. In: Walter Haug: Die Wahrheit der Fiktion. Studien zur weltlichen und geistlichen Literatur des Mittelalters und der frühen Neuzeit. Tübingen 2003, S. 426-445.

$28 \mathrm{Zu}$ diesem Aspekt vgl. Jan Assmann: Text und Kommentar. Einführung. In: Jan Assmann, Burkhard Bladigow (Hg.): Text und Kommentar. Archäologie der literarischen Kommunikation IV. München 1995, S. 9-33, bes. S. $19 \mathrm{f}$.

29 Für die mittelalterliche Literatur in der Volkssprache vgl. Nikolaus Henkel: Wann werden die Klassiker klassisch? Überlegungen zur Wirkungsweise und zum Geltungsbereich literarisch-ästhetischer Innovation im deutschen Hochmittelalter. In: Hans-Joachim Schmidt (Hg.): Tradition, Innovation, Invention. Fortschrittsverweigerung und Fortschrittsbewusstsein im 
indem der Kommentar als »auratische[s] Moment[ ] « ${ }^{30}$ den in der Überlieferung in der Regel (strukturell) herausgehobenen (Original-)Text erst als textus classicus inszeniert. ${ }^{31}$

In diesem Sinne repräsentiert der Kommentar eine kulturelle Konstante im Umgang mit der Tradierung gelehrter Bildungsinhalte und wird zum Signum einer »exegetische[n] Akkomodation des Textes « ${ }^{32}$ an veränderte gesellschaftliche Anforderungen und Institutionalisierungsprozesse. Er sichert die Geltung und Autorität des kommentierten Textes, indem er diesen sowohl in einem ordnenden, wissenssoziologisch perspektivierten Zugriff an gewandelte Verstehensbedingungen anpasst als auch die darin fixierten Wissensstrukturen über die Zeit konserviert in der Form eines »materialisierte[n] Gedächtnisse[s] «. ${ }^{33}$ In dieser Funktion markiert der Kommentar einen Speicheraspekt des verfügbaren Wissens, an dem ein markantes, synchron wie diachron produktives Spannungsverhältnis historisch beobachtbar wird: Als sprachlich-formale, inhaltlich-thematische Explikation des als erklärungsbedürftig angesehenen Ausgangstextes fixiert er ein historisches `Wissensstadium`, das dem Fundus kulturellen Wissens abhanden gekommene Kontexte durch eine simultane Amalgamierung mit den je zeitgenössischen Vermittlungsmodalitäten aktualisiert. In zeitlicher Retrospektive wird der Kommentar selbst kommentierungs- bzw. revisionsbedürftig, insofern er eine kontinuierliche Perpetuierung gemäß des je aktuell geltenden Wissensstandards und der Gebrauchsmodalitäten des (kommentierten) Textes erfordert. ${ }^{34}$

Mittelalter. Berlin, New York 2005, S. 441-467; Nikolaus Henkel: Wertevermittlung und Wissen in der Hand des Gelehrten. Sebastian Brant und sein Werk. In: Elke Brüggen u. a. (Hg.): Text und Normativität im deutschen Mittelalter. XX. Anglo-German Colloquium. Berlin, Boston 2012, S. 13-48.

30 Peter Strohschneider: Faszinationskraft der Dinge. Über Sammlung, Forschung und Universität. In: Denkströme 8 (2012), S. 9-26, hier: S. 20.

31 Vgl. Assmann: Text und Kommentar (s. Anm. 28), S. 19. Zur Indienstnahme dieser Funktion zur Eigenstilisierung siehe Aleida Assmann: Der Eigen-Kommentar als Mittel literarischer Traditionsstiftung. Zu Edmund Spensers The Shepheardes Calender. In: Aleida Assmann, Monika Gomille, Gabriele Rippl (Hg.): Sammler - Bibliophile - Exzentriker. Tübingen 1998, S. 355-373. 32 Assmann: Text und Kommentar (s. Anm. 28), S. 11.

33 Justin Stagl: Homo collector. Zur Anthropologie und Soziologie des Sammelns. In: Aleida Assmann, Monika Gomille, Gabriele Rippl (Hg.): Sammler - Bibliophile - Exzentriker. Tübingen 1998, S. 37-54, hier: S. 41.

34 Vgl. mit Blick auf die Frühe Neuzeit Julia Frick: Pluralisierung von Sinn. obscuritas als textinterpretative Kategorie in Kommentar und Übersetzung der Frühen Neuzeit. In: Susanne Köbele, Julia Frick (Hg.): wildekeit. Spielräume literarischer obscuritas im Mittelalter. Zürcher Kolloquium 2016. Berlin 2018, S. 413-435. 
Diese >Archivfunktion ${ }^{35}$ zeichnet sich durch eine symptomatische Ambivalenz aus: Indem der Kommentar im Text vorhandene, aber nicht explizit gemachte Sinnschichten erschließt, produziert er selbst beständig Mehrdeutigkeiten, die wiederum Versuche der Vereindeutigung der sobskuren` Sinnpluralität provozieren. ${ }^{36}$ Damit erscheint der Kommentar als Spiegel historischer Wissensformationen und zeitgenössisch virulenter Diskurse, die Auskunft geben können über die kultur- und sozialhistorischen Bedingtheiten ihrer jeweiligen Entstehungs- und Rezeptionskontexte. Weil Kommentare gerade innerhalb von Institutionen zu den traditionellen Formen intellektuell-diskursiver Kommunikation und Verständigung über kulturelle $>$ Leit-Texte gehören, ${ }^{37}$ bieten sie einen Reflex der (Bildungs-) Interessen einer Gemeinschaft.

Der Funktionstypus Kommentar reagiert also nicht nur auf innerliterarische Diskursverschiebungen und Akzentuierungen oder poetologische Diskussionen, sondern auch auf Veränderungen hinsichtlich der Funktionszusammenhänge und Benutzungskontexte, in die ein literarisches Werk Eingang findet. Sein Sinnzentrum lässt sich als das eines »Zeitspeicher[s] ${ }^{38}$ beschreiben, das vergangene intellektuelle Formationen dokumentiert und ein angemessenes Instrument zur Rekonstruktion kollektiver Geschichte bietet. ${ }^{39}$ Die Spielräume divergierender Bedeutungskonstitution sollen im Folgenden an einem exemplarischen Modellfall aufgezeigt werden: Grundlage ist ein exzeptionelles Beispiel mittelalterlicher Kommentierung des 14. Jahrhunderts, das aufgrund seines Status als `Gegenpol $z u$ den traditionellen Paradigmen differenziertere Einblicke in die sozialhistorische Bedingtheit der jeweils getroffenen Aussagen erlaubt.

35 Zum Funktionstypus des Archivs vgl. Moritz Baßler: Die kulturpoetische Funktion und das Archiv. Eine literaturwissenschaftliche Text-Kontext-Theorie. Tübingen 2005; Markus Friedrich: Die Geburt des Archivs. Eine Wissensgeschichte. München 2013.

36 Zur obscuritas in interdisziplinär-historischer Perspektive vgl. Susanne Köbele, Julia Frick (Hg.): wildekeit. Spielräume literarischer obscuritas im Mittelalter. Zürcher Kolloquium 2016. Berlin 2018.

37 Zur Bedeutung der Kommentierung im Rahmen mittelalterlicher Schullektüre vgl. in germanistisch-mediävistischer Hinsicht Nikolaus Henkel: Deutsche Übersetzungen lateinischer Schultexte. Ihre Verbreitung und Funktion im Mittelalter und in der frühen Neuzeit. Mit einem Verzeichnis der Texte. München 1988.

38 Christine Blättler, Ulrike Vedder: Dynamik und Ordnung der Sammlung - Strategie, Spiel und Verlust. Zur Einleitung. In: Sarah Schmidt (Hg.): Sprachen des Sammelns. Literatur als Medium und Reflexionsform des Sammelns. Paderborn 2016, S. 199-204, hier: S. 203.

39 Vgl. in anderem Zusammenhang Adrian Stähli: Sammlungen ohne Sammler. Sammlungen als Archive des kulturellen Gedächtnisses im antiken Rom. In: Aleida Assmann, Monika Gomille, Gabriele Rippl (Hg.): Sammler - Bibliophile - Exzentriker. Tübingen 1998, S. 55-86. 


\section{Erwartungsbrüche in der Mystik: Lateinisch- deutsche Sprachlogiken in der Kommentierung zum Granum sinapis}

Das Granum sinapis gilt in der Forschung »als Höhepunkt der volkssprachlichen geistlichen Lyrik des Mittelalters «. ${ }^{40}$ Diese Sonderstellung beruht einerseits auf formalen Kriterien, andererseits resultiert sie aus überlieferungspraktischen Befunden. Das deutsche Gedicht, das die germanistischmediävistische Forschung seit den wegweisenden Arbeiten Kurt Ruhs in der Regel als Kontrafaktur betrachtet, ${ }^{41}$ weist nämlich in metrischer Hinsicht eine Bauform auf, die einigen Sequenzentypen des 12. Jahrhunderts nahekommt, die Adam von St. Victor zugeschrieben werden. ${ }^{42}$ Aufgrund dieses Umstands wird das Granum sinapis auch als >deutsche Sequenz ${ }^{43}$ oder >deutsches Lied ${ }^{44}$ verhandelt - Gattungsbegriffe, die infolge des ihnen zugrundeliegenden Merkmals der Sangbarkeit spezifische Gebrauchskontexte des deutschen Gedichts implizieren, die, wie musikologische Studien gezeigt haben, kritisch stimmen dürften, ${ }^{45}$ die aber auch angesichts der Überlieferung zum mindesten bedenkenswert sind. Darauf komme ich weiter unten zurück.

40 Susanne Köbele: Vom `Schrumpfen`der Rede auf dem Weg zu Gott. Aporien christlicher Ästhetik (Meister Eckhart und das Granum sinapis - Michel Beheim - Sebastian Franck. In: Poetica 36 (2004), S. 119-147, hier: S. 121.

41 Vgl. Kurt Ruh: Textkritik zum Mystikerlied Granum sinapis. In: Kurt Ruh: Kleine Schriften. Bd. 2: Scholastik und Mystik im Spätmittelalter. Hg. von Volker Mertens. Berlin, New York 1984, S. 77-93 (zuerst erschienen in: Festschrift Josef Quint anläßlich seines 65. Geburtstages überreicht. Hg. von Hugo Moser, Rudolf Schützeichel, Karl Stackmann. Bonn 1964, S. 169-185); Kurt Ruh: Granum sinapis. In: ${ }^{2}$ VL 3 (1981), Sp. 220-224; Kurt Ruh: Meister Eckhart. Theologe, Prediger, Mystiker. München ${ }^{2} 1989$, S. 47-59 (Kap. 4: Dionysische Mystik: Granum sinapis).

42 Vgl. Markus Steffen: Das Granum sinapis und die Sequenzen Adams von St. Victor. In: PBB 129 (2007), S. 402-418. Zur Zuschreibungsproblematik der Sequenzen an Adam von St. Viktor siehe Margot E. Fassler: Who was Adam of St. Victor? The evidence of the sequence manuscripts. In: Journal of the American Musicological Society 37 (1984), S. 233-269.

43 So bei Ruh: Meister Eckhart. Theologe, Prediger, Mystiker (s. Anm. 41), S. 47; Köbele: Vom 'Schrumpfen ‘ der Rede auf dem Weg zu Gott (s. Anm. 40), S. 121.

44 Walter Haug: Meister Eckhart und das Granum sinapis. In: Horst Brunner, Werner Williams-Krapp (Hg.): Forschungen zur deutschen Literatur des Spätmittelalters. Festschrift Johannes Janota. Tübingen 2003, S. 73-94, hier: S. 73.

45 Steffen (Das Granum sinapis und die Sequenzen Adams von St. Victor [s. Anm. 42], S. 402) fragt danach, »ob es tatsächlich möglich ist, die eine Melodie aus den Adam zugeschriebenen [...] Sequenzen herauszufiltern.«. 
Das Granum sinapis ist in zehn Handschriften des 14. und 15. Jahrhunderts erhalten. ${ }^{46}$ Die weitaus älteste ist eine um 1400 zusammengefügte Komposithandschrift (Basel, Universitätsbibliothek, Cod. B IX 24), ${ }^{47}$ die eine sekundär hergestellte Buchbindersynthese repräsentiert. Es handelt sich dabei um drei ursprünglich als Einzelteile konzipierte, im 14. Jahrhundert verfasste Faszikel überwiegend lateinisch-theologischen Gehalts, die wohl erst in der Basler Kartause (nach der Gründung 1401) in einem Band zusammengefasst worden sind. ${ }^{48}$ Der zweite Faszikel (fol. $27^{\mathrm{r}}-40^{\mathrm{v}}$ ), der das Granum sinapis enthält, wird in die Jahre 1320/30 datiert ${ }^{49}$ - eine Konkretheit, die im Hinblick auf den sozialhistorischen Kontext eine zentrale Rolle spielt. Wie Kurt Ruh gezeigt hat, führt die Basler Überlieferung des Textes »unmittelbar an das Original heran[ ] «; ${ }^{50}$ er verortete das Gedicht aufgrund der charakteristischen Schreibsprache sowie seiner mystisch-spekulativen Ausrichtung im mitteldeutsch-thüringischen Raum, also der »Wirkungsstätte des jüngeren Eckhart«, und zog dessen Verfasserschaft in Betracht. ${ }^{51}$ Diese Zuschreibung wird von der Forschung mittlerweile skeptisch gesehen und auf der Basis inhaltlicher, auf die Übereinstimmung mit Eckharts Lehrsätzen zielender Plausibilitätskriterien zurückgewiesen. ${ }^{52}$ Der Überlieferungsbefund zum Granum sinapis lässt allerdings die Frage auf-

46 Der jüngst aufgefundene Textzeuge T (Torún, Universitätsbibliothek, Rps. 75) ist beschrieben bei Ralf G. Päsler: Ein neuer Textzeuge des Granum sinapis aus der ehem. Königsberger Dombibliothek. In: ZfdA 136 (2007), S. 58-67. Dort ist auch die Zusammenstellung der weiteren Überlieferungszeugen verzeichnet (ebd., S. 61f.). Vgl. auch Ruh: Textkritik zum Mystikerlied Granum sinapis (s. Anm. 41), S. 78f., sowie Bruno Jahn: Granum sinapis. In: Deutsches Literatur-Lexikon. Das Mittelalter. Autoren und Werke nach Themenkreisen und Gattungen. Bd. 2: Das geistliche Schrifttum des Spätmittelalters. 1. Hälfte 14. Jh. Hg. von Wolfgang Achnitz. Berlin, Boston 2011, Sp. 1-4.

47 Zur Beschreibung vgl. Max Burckhardt, Gustav Meyer: Die mittelalterlichen Handschriften der Universitätsbibliothek Basel. Beschreibendes Verzeichnis. Abteilung B: Theologische Pergamenthandschriften. Bd. 2. Signaturen B VIII 11-B XI 26. Basel 1966, S. 336-348.

48 Dazu Judith Theben: Die mystische Lyrik des 14. und 15. Jahrhunderts. Untersuchungen Texte - Repertorium. Berlin, New York 2010, S. 189.

49 Vgl. Ruh: Granum sinapis (s. Anm. 41), Sp. 222.

50 Ruh: Textkritik zum Mystikerlied Granum sinapis (s. Anm. 41), S. $88 \mathrm{f}$.

51 "Ich habe heute kaum mehr Bedenken, in ihm [sc. Meister Eckhart] nicht nur den geistigen Anreger, sondern den wirklichen Verfasser zu sehen.« Ruh: Meister Eckhart. Theologe, Prediger, Mystiker (s. Anm. 41), S. $49 \mathrm{f}$.

52 So schon Bindschedler in ihrer Edition des Granum sinapis und dessen lateinischem Kommentar: Maria Bindschedler: Der lateinische Kommentar zum Granum sinapis. Basel 1949, S. 12f. - In jüngerer Zeit hat vor allem Walter Haug die Verfasserfrage vehement mit »Nein « (gegen eine Zuschreibung an Meister Eckhart) beantwortet, das Granum sinapis aber dennoch in Eckharts Umkreis gestellt. Haug: Meister Eckhart und das Granum sinapis (s. Anm. 44), S. 74. Einen ähnlichen Standpunkt vertritt Köbele: Vom sSchrumpfen` der Rede auf dem Weg zu Gott (s. Anm. 40), S. 131. 
kommen, ob unsere Erwartungen an eine konzeptuelle Homogenität eines >Werkganzen`, wie sie in diesem Zusammenhang immer wieder als Argument in Anschlag gebracht wird, angesichts der Alterität der mittelalterlichen Literaturproduktion mit ihren evidenten Spannungen und Überlagerungen heterogener Elemente als historisch adäquat gelten können. ${ }^{53}$

Bemerkenswert ist das Granum sinapis insbesondere aufgrund der außergewöhnlichen Konstellation in der ältesten Basler Handschrift. Denn darin tritt es nicht als eigenständiger, geschlossener Text in Erscheinung, sondern ist in einen lateinischen Kommentar dergestalt inkorporiert, dass sich die jeweils ausführlich besprochenen Einzelverse erst in einem mentalen Prozess des Abschreitens und Zusammenfügens bei der Lektüre zu einer Einheit formieren. Dieser Prozess wird in den modernen Editionen, ${ }^{54}$ die Text und Kontext separieren, im Sinne einer (selbstverständlich notwendigen) leichteren Rezipierbarkeit des deutschen Gedichts aufgelöst - leider mit einem auch in anderen Bereichen oftmals zu beobachtenden Effekt, dass im Rahmen der Interpretationsbemühungen der Forschung der lateinische Text weit hinter den volkssprachigen zurücktritt, obwohl in der ältesten erhaltenen Form zumindest von einer konzeptionellen Einheit auszugehen ist, wenn nicht gar die Priorität auf dem lateinischen >Rahmen liegt. Dass ein volkssprachiger Text einen lateinischen Kommentar im gelehrten Duktus erhält, ist im Mittelalter an sich schon ein exzeptioneller Fall und insofern ein veritabler Erwartungsbruch. ${ }^{55}$ Dass der Kommentar aber geradezu den ihm traditionel-

Dass sich »[ü]ber den Verfasser [...] Genaueres nicht sagen « lasse, betont Alois M. Haas: Sermo Mysticus. Studien zu Theologie und Sprache der deutschen Mystik, Freiburg i.Üe. 1979, S. 305.

53 Vgl. in einem kontextorientierten Ansatz Niklaus Largier: Von Hadewijch, Mechthild und Dietrich zu Eckhart und Seuse? Zur Historiographie der >deutschen Mystik und der >deutschen Dominikanerschuler. In: Walter Haug, Wolfram Schneider Lastin (Hg.): Deutsche Mystik im abendländischen Zusammenhang. Neu erschlossene Texte, neue methodische Ansätze, neue theoretische Konzepte. Kolloquium Kloster Fischingen. Tübingen 2000, S. 93-117.

54 Vgl. Bindschedler: Der lateinische Kommentar zum Granum sinapis (s. Anm. 52), und die modifizierte Ausgabe des deutschen Textes durch Ruh: Textkritik zum Mystikerlied Granum sinapis (s. Anm. 41).

55 Siehe zum traditionellen Diskurs des latein-deutschen Sprachtransfers exemplarisch Britta Bußmann, Albrecht Hausmann, Annelie Kreft, Cornelia Logemann (Hg.): Übertragungen. Formen und Konzepte von Reproduktion in Mittelalter und Früher Neuzeit. Berlin, New York 2005; Joachim Heinzle (Hg.): Übersetzen im Mittelalter. Cambridger Kolloquium 1994. Berlin 1996; Nikolaus Henkel, Nigel F. Palmer (Hg.): Latein und Volkssprache im deutschen Mittelalter. 11001500. Regensburger Colloquium 21.-24. September 1988. Tübingen 1992. - Im europäischen Kontext vgl. Michael Baldzuhn, Christine Putzo (Hg.): Mehrsprachigkeit im Mittelalter. Kulturelle, literarische, sprachliche und didaktische Konstellationen in europäischer Perspektive. Mit Fallstudien zu den Disticha Catonis. Berlin 2011. - Zum weitaus seltener zu beobachtenden Phänomen des Transfers aus dem Lateinischen in die Volkssprachen vgl. Françoise Fery-Hue (Hg.): 
lerweise auch graphisch übergeordneten textus dominiert, ${ }^{56}$ ist ein Überlieferungsbefund, der auf eine historische Problemkonstellation verweist, welcher sich mit einer ausschließlich literaturwissenschaftlich operierenden Analyse nur in begrenztem Maße begegnen lässt. ${ }^{57}$

Ausgangspunkt der Überlegungen ist zunächst die Thematik, um die das Granum sinapis kreist: ${ }^{58}$ das »Repräsentationsparadox « ${ }^{59}$ einer ontologischen Grundkonstante, deren Sinnzentrum die Problematik um den anwesend-verborgenen Gott bildet. In extremer sprachlicher Verknappung bieten die acht Strophen des Gedichts den Versuch, »die Immanenz und Transzendenz Gottes zusammenzudenken «. ${ }^{60}$ Der mystischen Einheitsspekulation, die der Text durchspielt, liegt die Kernbestimmung der negativen Theologie in der Tradition des Dionysius Areopagita zugrunde, ${ }^{61}$ nach der alles Sprechen über die Transzendenz aufgrund der naturgemäßen Insuffizienz zuschreibender Aussagen nur über den negativ-affirmativen Modus möglich ist: In einer »transgressive[n] Aussageweise «, ${ }^{62}$ die sprachlich-gedanklich über einfache Gegensätze und Kontraste hinausführt und in einem dynamischen Prozess der Sinnaufhebung Sinn produziert. Die ersten drei Strophen thematisieren die Einheit Gottes, während die Strophen vier bis acht in zunehmender Hinwendung zum Rezipienten den Weg zur Vereinigung der Seele mit Gott beschreiben. ${ }^{63}$ In charakteristischen Strukturparadoxien modelliert das Gedicht eine Enthobenheit von Zeit und Raum, sowohl im Hinblick auf die als unveränderliche Einheit konzipierte Gottesgeburt (processio sine variatione) als auch in Bezug auf die progressive Selbstentäußerung der Seele, die im Heraustreten aus der Zeit und

Habiller en latin. La traduction de vernaculaire en latin entre Moyen Âge et Renaissance. Paris 2018.

$56 \mathrm{Zu}$ den `klassischen Typen der hoch- und spätmittelalterlichen Text-Kommentar-Arrangements vgl. Gerhard Powitz: Textus cum commento. In: Codices manuscripti 5 (1979), S. 80-89. 57 Das ist mit dem Hinweis auf »die grundsätzliche Ambiguität historischer Befunde und Wertungen« im hermeneutischen Prozess angedeutet bei Köbele: Vom `Schrumpfen` der Rede auf dem Weg zu Gott (s. Anm. 40), S. 133 f.

58 Im Folgenden zitiert nach Ruh: Meister Eckhart. Theologe, Prediger, Mystiker (s. Anm. 41), S. 47-49. Vgl. auch Ruh: Textkritik zum Mystikerlied Granum sinapis (s. Anm. 41), S. 80 f. u. 91-93.

59 Köbele: Vom `Schrumpfen` der Rede auf dem Weg zu Gott (s. Anm. 40), S. 121.

60 Ebd., S. 123.

61 Vgl. Kurt Ruh: Geschichte der abendländischen Mystik. Bd. 1: Die Grundlegung durch die Kirchenväter und die Mönchstheologie des 12. Jahrhunderts. München 1990, bes. S. 31-82.

62 Köbele: Vom `Schrumpfen` der Rede auf dem Weg zu Gott (s. Anm. 40), S. 124.

63 Zur Analyse der einzelnen Strophen unter mystagogischen bzw. poetischen Gesichtspunkten vgl. Haas: Sermo Mysticus (s. Anm. 52), S. 301-329, sowie Haug: Meister Eckhart und das Granum sinapis (s. Anm. 44), S. 73-94. 
Zeitlichkeit eine Vernunftlogik ausschließt. Dabei wird der durative Aspekt einer andauernden Vergangenheit und damit je aktuell-gegenwärtigen Heilsgeschichte durch entsprechende Tempusmarker geleistet (In dem begin / hô uber sin / ist ie daz wort I,1-3), ${ }^{64}$ die die Zeitebenen dynamisieren (dâ ie begin begin gebar I,5). Die spezifische Bildsprache operiert mit 'Sprengmetaphern $<,{ }^{65}$ die den Spielraum prädikativer Attribution jenseits der Vorstellungskraft ins Unmögliche steigern. Sie zielen, wie z. B. das Paradox des ewigen Beginns (I,5) oder des weglosen Weges (genk âne wek / den smalen stek VII,8f.), statt einer Differenz auf eine Integration des Gegensätzlichen und streben über jeden Vorgang (sprachlicher) Relationierung hinaus. Das Granum sinapis reflektiert die "grundsätzliche Ineffabilität Gottes«,indem es diesen in der Form einer negatio negationis »dem objektsprachlichen Bereich systematisch entzieht $«{ }^{66}$ Die letzte Strophe setzt mit einer expliziten Appellstruktur den Vorgang permanenter Selbstaufgabe, der in der Vereinigung der Seele mit gotis nicht mündet, in den Bereich exklusiver Erfahrung um:

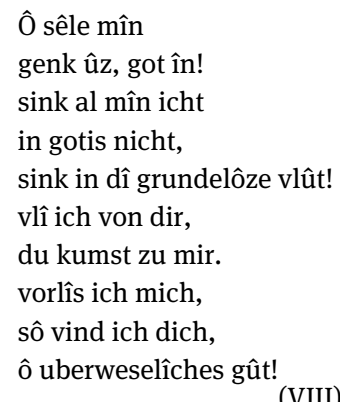

Das deutsche Gedicht führt in einer parataktisch intensivierten Dichte in die Aporien aller menschlichen Reflexion über das Erkennen des Deus superignotus hinein. Die ihnen auf der sprachlichen Ebene korrespondierende paradoxe Metaphorik weist das »traditionell verräumlicht gedacht $[\mathrm{e}] \ll^{67}$ Einheitskonzept von Immanenz und Transzendenz ab und überführt es in die Vorstellung einer Erfahrung der mystischen Unio durch Erfahrung der »Inadäquatheit» des Spre-

$64 \mathrm{Vgl}$. die Diskussion zum Zitat aus Io 1,1 (In principio erat verbum) der ersten Strophe bei Haug: Meister Eckhart und das Granum sinapis (s. Anm. 44), bes. S. 75-77, und Ruh: Meister Eckhart. Theologe, Prediger, Mystiker (s. Anm. 41), S. 50.

$65 \mathrm{Zu}$ Blumenbergs Konzept der `Sprengmetaphorikı in Bezug auf die deutschsprachige Mystik des Mittelalters vgl. Susanne Köbele: Bilder der unbegriffenen Wahrheit. Zur Struktur mystischer Rede im Spannungsfeld von Latein und Volkssprache. Tübingen, Basel 1993, bes. S. 67. 66 Haas: Sermo Mysticus (s. Anm. 52), S. 319 u. 321.

67 Köbele: Vom `Schrumpfen` der Rede auf dem Weg zu Gott (s. Anm. 40), S. 130. 
chens von Gott. ${ }^{68}$ Damit ist zugleich die Grenze zum zeitgenössisch geltenden orthodox-theologischen Diskurs überschritten - sie gehört zu denjenigen Grenzen, die im Spätmittelalter »auch inquisitorisch durchgesetzt werden $«{ }^{69}$ Diesen Aspekt gilt es gleich zu bedenken.

Die Forschung hat mit Nachdruck darauf hingewiesen, dass sich der überwiegende Teil der im Granum sinapis enthaltenen Vorstellungen und Bildkomplexe "mit Eckhartschen Ausführungen paraphrasieren lasse $^{70}$ ein Befund, der auch für das sprachlich-begriffliche Material des Textes ganz grundsätzlich gilt: »Man kann das Granum sinapis in seinen Vorstellungen und Formulierungen so gut wie vollständig in der Tradition mystischen Denkens und Darstellens verorten. " ${ }^{71}$ Einzig die Tatsache, dass die Vorstellung der Gottesgeburt in der Seele als ontologische Grundkategorie der Eckhartschen Mystik ausgespart sei, sowie der Tenor der letzten Strophe, die die bis dahin im Gedicht herausgestellte Paradoxie durch die implizierte Möglichkeit der Gotteserkenntnis unterlaufe, erschienen im Hinblick auf eine mögliche Autorschaft Eckharts, für die Ruh aus plausiblen Gründen plädiert hatte, geradezu als `Zumutung.$^{72}$ Als problematisch an dieser Argumentation erweist sich die fehlende Berücksichtigung des medialen Charakters des Granum sinapis: erstens der Volkssprache gegenüber der Latinität als derjenigen Sphäre, in der traditionellerweise systematische Aussagen verhandelt werden; zweitens der potentiell sangbaren Form, die das diskursiv verfügbare Material in prägnanter Kürze präsentiert; drittens der besonderen Überlieferungssituation von Text und Kommentar sowohl in der ältesten, als originalnah eingestuften Basler Handschrift als auch in den restlichen Überlieferungszeugen. ${ }^{73}$ Jedenfalls prekär an einem solchen Nachweis, der allein mit Kohärenzerwartungen an ein systematisch ausgearbeitetes 'Theoriekonzepts argumentiert, ist darüber hinaus die einseitige Verpflichtung des Textes auf eine widerspruchsfreie Konformität mit der spezifischen Theologie Eckharts, deren unter-

68 Haas: Sermo Mysticus (s. Anm. 52), S. 328. Siehe dazu auch Burkhard Hasebrink: Diesseits? Eucharistie bei Meister Eckhart im Kontext der Debatte um >Präsenzkultur«. In: Christian Kiening (Hg.): Mediale Gegenwärtigkeit. Zürich 2007, S. 193-205.

69 Köbele: Vom `Schrumpfen` der Rede auf dem Weg zu Gott (s. Anm. 40), S. 122.

70 Haas: Sermo Mysticus (s. Anm. 52), S. 314. Grundlegend Ruh: Meister Eckhart. Theologe, Prediger, Mystiker (s. Anm. 41), S. 54, der aus dem Granum sinapis »religiöse Zentralaussage[n] Eckharts« destilliert.

71 Haug: Meister Eckhart und das Granum sinapis (s. Anm. 44), S. 84.

72 Das Granum sinapis könne nicht »Eckhart selbst zugemutet werden«. Ebd., S. 91. Denn die letzte Strophe dokumentiere die »Vereinseitigung des Eckhartschen Konzepts« und sei in diesem Sinne als »völlig anti-eckhartisch" einzustufen. Ebd., S. 92.

73 Vgl. dazu unten S. 198f. 
schiedliche Aspekte das Granum sinapis bruchlos abbilden müsse. ${ }^{74}$ Dass dies »eher ein Postulat der neuzeitlichen Erwartung als der mittelalterlichen Arbeitsweise« darstellt, hat Niklaus Largier zu bedenken gegeben. ${ }^{75}$ Vor diesem Hintergrund wäre zu überlegen, ob eine von den genannten medialen Kriterien separierte Betrachtung des deutschen Gedichts den von der Forschung getroffenen Rückschluss und dessen umfassenden Geltungsanspruch ausreichend rechtfertigt.

Die Entstehung des Granum sinapis wird in der Regel um 1300 im thüringischen Raum situiert, möglicherweise in einem monastischen Umfeld - »eines unter dominikanischem Einfluss stehenden Nonnenklosters «. ${ }^{76}$ Doch sowohl diese Datierung als auch die Zuweisung des Gedichts an einen »begabte[n] Lyriker und hochgebildete[n] Theologen ${ }^{77}$ aus dem engeren Umfeld Meister Eckharts bleiben rein hypothetischer Natur. Es fehlt auch jegliche Evidenz dafür, dass das deutsche Gedicht »ursprünglich auf einen Kommentar nicht angewiesen war ${ }^{78}$ - die Überlieferung lehrt vielmehr das Gegenteil: Die integrale Konzeption aus Text und Kommentar bildet eine dermaßen stabile Konstante in der handschriftlichen Tradierung, ${ }^{79}$ dass sie die Annahme einer sehr zeitnahen, wenn nicht gar simultanen Entstehung des deutschen Gedichts und lateinischen Kommentars nahelegt. ${ }^{80}$ Gerade der Aspekt der tendentiellen Sangbarkeit, der als Argument für die Entstehung des Textes im Umfeld dominikanischer Frauenkonvente diente, ${ }^{81}$ erscheint angesichts neuerer musikologischer Studien als diskutabel: Markus Steffen hat das von der germanistisch-mediävistischen Forschung für die metrische Form des Granum sinapis in Anschlag gebrachte »autochthone[ ]

74 »Was mich veranlaßt, den Text auf der Basis des bislang interpretatorisch Geleisteten nochmals durchzugehen, ist die Frage, ob das Konzept des Granum sinapis tatsächlich mit Eckharts Theologie zur Deckung zu bringen ist«. Haug: Meister Eckhart und das Granum sinapis (s. Anm. 44), S. 74.

75 Largier: Von Hadewijch, Mechthild und Dietrich zu Eckhart zu Seuse (s. Anm. 53), S. 96.

76 Haas: Sermo Mysticus (s. Anm. 52), S. 306.

77 Haug: Meister Eckhart und das Granum sinapis (s. Anm. 44), S. 90.

78 Ebd., S. 85.

79 In der Überlieferung ist das Granum sinapis - bis auf eine einzige Ausnahme - ausschließlich mit einem Paratext verbunden, entweder dem lateinischen Kommentar oder mit der deutschsprachigen andechtige[ $n$ ] betrachtunge. Vgl. die Übersicht bei Theben: Die mystische Lyrik des 14. und 15. Jahrhunderts (s. Anm. 48), S. $187 \mathrm{f}$. Zwei fragmentarisch erhaltenen Textzeugen ist nicht mehr zu entnehmen, ob dem deutschen Gedicht ein Kommentar beigegeben gewesen ist.

80 So schon Ruh (Granum sinapis [s. Anm. 41], Sp. 222): Der Kommentar "muß fast so alt sein wie das Lied«.

81 Haas: Sermo Mysticus (s. Anm. 52), S. 306, sieht als Verfasser »am ehesten wohl ein[en] Spiritual eines unter dominikanischem Einfluß stehenden Nonnenklosters« an. 
Modell« aus dem Adam von St. Victor zugeschriebenen Sequenzrepertoire einer korrigierenden Einschätzung zugeführt. ${ }^{82}$ Anhand eines Abgleichs der formalen Charakteristika der mit dem Granum sinapis in Verbindung gebrachten Paradigmen kann er zeigen, dass alle Sequenzen dieses Typus in den Pariser Zentren und in St. Victor jeweils mit unterschiedlichen Melodien überliefert sind. ${ }^{83}$ Angesichts dieses Befundes erweise sich die Rekonstruktion »der einen Melodie [...], nach der das Granum sinapis gesungen wurde« als aporetisch. ${ }^{84}$ Daher könne es zurecht weder als Kontrafaktur noch als >deutsche Sequenz` gelten, setze doch diese Zuweisung eine musikalische Realisierung des Textes voraus. Auf einen solchen liturgischen oder paraliturgischen Gebrauch bietet allerdings die »handschriftliche Überlieferung des Granum sinapis keinerlei Hinweise $«{ }^{85}$ Die enge Verknüpfung von Text und Kommentar dokumentiert vielmehr, dass das Granum sinapis nicht in habitualisierter Performanz in der monastischen Gemeinschaft rezipiert worden sein dürfte, sondern primär als Gegenstand gelehrter Reflexion. ${ }^{86}$

Die Erkenntnis dieser alternativen Funktionalisierung führt zu Kurt Ruhs Hypothese zurück. Sein Argument, demnach Meister Eckhart »nicht nur als geistiger Anreger, sondern wirklicher Verfasser « ${ }^{87}$ des Granum sinapis infrage komme, ging davon aus, dass Eckhart die unterschiedlichen, in Paris und St. Victor gebräuchlichen Sequenztypen und deren »heterogene[n] melodische[n] Gebrauch « ${ }^{88}$ während seiner Aufenthalte in Paris kennengelernt und für einen deutschen Text adaptiert hatte. ${ }^{89}$ Dafür spricht die Anbindung des Textes nicht an die eine spezifische Melodie, sondern die Möglichkeit unterschiedlicher gesanglicher Umsetzung, wie sie auch in den Pariser Zentren für

82 Steffen: Das Granum sinapis und die Sequenzen Adams von St. Victor (s. Anm. 42), S. 409.

83 Ebd., S. 406.

84 Ebd., S. 417.

85 Ebd. Siehe zur Überlieferung deutscher geistlicher Lyrik einschlägig Johannes Janota: Studien zu Funktion und Typus des deutschen geistlichen Liedes im Mittelalter. München 1968.

86 »Was die melodische Komponente angeht, stellt sich allerdings die Frage, ob man sich den Text allein in Anbetracht seiner metrischen Form (die im Bereich mittelhochdeutscher Dichtung wohl eine singuläre Erscheinung ist) zwingend als gesungenes Lied vorzustellen hat." Steffen: Das Granum sinapis und die Sequenzen Adams von St. Victor (s. Anm. 42), S. 417. Siehe dazu auch unten, S. 199 u. 202.

87 Ruh: Meister Eckhart. Theologe, Prediger, Mystiker (s. Anm. 41), S. 50.

88 Steffen: Das Granum sinapis und die Sequenzen Adams von St. Victor (s. Anm. 42), S. 417.

$89 \mathrm{Zu}$ Eckharts Wirkungsstätten vgl. einschlägig Kurt Flasch: Meister Eckhart. Philosoph des Christentums. München 2010. Auffällig ist allemal, dass es sich beim Granum sinapis um das einzige mystische >Lied in der Volkssprache handelt, das einem solchen Schema liturgischen oder paraliturgischen Charakters jedenfalls nachgebildet zu sein scheint. Vgl. dazu Theben: Die mystische Lyrik des 14. und 15. Jahrhunderts (s. Anm. 48), S. 186-191. 
ähnliche metrische Muster nachweisbar ist. ${ }^{90}$ Der Transfer der formal als sangbar konzipierten volkssprachigen mystischen Einheitsspekulationen in einen gelehrt-theologischen, lateinisch grundierten Kontext dürfte sich in den 1320er Jahren, in die auch die Niederschrift des entsprechenden Faszikels des Basler Manuskripts datiert wird, ${ }^{91}$ vollzogen haben: Hier erscheint das deutsche Gedicht in seiner ältesten Gestalt als in den lateinischen Kommentar eingelagert. Damit hat es, was die anhand der handschriftlichen Überlieferung rekonstruierbaren Gebrauchskontexte betrifft, die Sphäre gruppenspezifischer gesanglicher Rezeption verlassen. Gerade die Überlieferung mit bzw. korrekter: innerhalb des lateinischen Kommentars sowie dessen spezifische apologetische Tendenz bieten plausible Anhaltspunkte dafür, das Zustandekommen dieser Symbiose im Gefolge des gegen Meister Eckhart geführten Inquisitionsprozesses in Betracht zu ziehen. $^{92}$

In den drei zwischen 1325 und 1326 zusammengestellten Listen, ${ }^{93}$ die als Basis für die Anklage des Kölner Inquisitionsgerichts dienten, wurden rund 108 Irrtümer aus Eckharts lateinischen und volkssprachigen Schriften sowie Predigten als häretisch bzw. häresieverdächtig inkriminiert. ${ }^{94}$ Das Verfahren, in dessen Zuge Eckhart in der Dominikanerkirche zu Köln »eventuelle Irrtümer [widerrief] und mögliche Missverständnisse [beklagte] «, ${ }^{95}$ wurde 1327 nach Avignon verlagert; nach Eckharts Tod erschien am 27. März 1329 die päpstliche Bulle In Agro Dominico, worin 17 Sätze als `häretisch`, 11 als >häresieverdächtig` verurteilt wurden. ${ }^{96}$ In seiner Verteidigungsschrift, die Eckhart als Grundlage für

90 Vgl. Steffen: Das Granum sinapis und die Sequenzen Adams von St. Victor (s. Anm. 42), S. 409-417.

91 Vgl. oben, S. 185.

92 Siehe dazu Flasch: Meister Eckhart (s. Anm. 89), S. 276-321. Zu den Prozessakten vgl. Loris Sturlese (Hg.): Acta Echardiana. LW V, 3-4 Lieferung (S. 196-240); 5-8 Lieferung (S. 241-520). Stuttgart 1988 u. 2000. Dazu Loris Sturlese: Die Kölner Eckhartisten. Das Studium generale der deutschen Dominikaner und die Verurteilung der Thesen Meister Eckharts. In: Albert Zimmermann (Hg.): Die Kölner Universität im Mittelalter. Geistige Wurzeln und soziale Wirklichkeit. Berlin, New York 1989, S. 192-211.

93 Vgl. dazu Susanne Köbele: Emphasis, überswanc, underscheit. Zur literarischen Produktivität spätmittelalterlicher Irrtumslisten (Eckhart und Seuse). In: Peter Strohschneider (Hg.): Literarische und religiöse Kommunikation in Mittelalter und Früher Neuzeit. DFG-Symposion 2006. Berlin, New York 2009, S. 969-1002.

94 Vgl. Flasch: Meister Eckhart (s. Anm. 89), S. 277.

95 Ebd.

96 Vgl. die Ausgabe von Heinrich Denzinger, Peter Hünermann (Hg.): Enchiridion symbolorum definitionum et declarationum de rebus fidei et morum. Freiburg i. Br. ${ }^{37} 1991$, S. 399-404. Zur deutschen Übersetzung siehe Meister Eckhart. Deutsche Predigten und Traktate. Hg. und übers. von Josef Quint. München 1979, S. 449-455. 
seine Rede vor den Kölner Richtern am 26. September 1326 diente, ${ }^{97}$ verweist er immer wieder auf die locutio emphatica als Richtschnur seines sprachlich-gedanklichen Handelns. ${ }^{98}$ Die emphatische Redeweise knüpft er dabei an den Modus des Hymnischen; wie dieser habe sie »das Ziel, Gottes Güte und Liebe zu preisen «, und repräsentiere insofern eine »unmittelbare Wahrheit von absoluter Reichweite ${ }^{99}$ Gerade diese locutio emphatica wird im Granum sinapis auf engstem Raum realisiert, sodass sie den Text einem hymnisch-poetischen Sprechakt annähert, der mit einer effektvollen Klanglichkeit arbeitet. Zugleich generiert sie einen - zumal durch die Mehrdeutigkeit der volkssprachigen Formulierungen bedingten - »Unbestimmtheitsspielraum «, ${ }^{100}$ aufgrund dessen das Gesagte, nach dem Muster der inkriminierten Sätze, unter »offensichtliche[n] Legitimierungsdruck « gerät. ${ }^{101}$ Und hier kommt die »apologetische Funktion « ${ }^{102}$ des lateinischen Kommentars zum Granum sinapis ins Spiel.

Der Kommentar zeichnet sich durch einige Spezifika im Hinblick auf sprachlich-formale Operationen der Exegese aus. In der Tradition der Quaestio-Kommentare, der scholastischen Form einer wissenschaftlichen Diskussion, ${ }^{103}$ entfaltet er eine dialektische Methode der Textauslegung, die auf der Basis einer hypothetisch vorausgesetzten Dissonanz mögliche Perspektiven hinsichtlich der Sinnkonstitution diskutiert. Richtschnur ist ein den Strukturprinzipien der Logik verpflichtetes Verifikationsprinzip, nach dem die vorgebrachten gegensätzlichen Thesen plausibilisiert und damit einer Entscheidung zugeführt werden. Das heißt, dass die Grundausrichtung des Kommentars zum Granum sinapis darauf zielt, den mehrdeutigen, weil begrifflich nicht strikt festgelegten Charakter der volkssprachigen Lexeme, Syntagmen oder syntaktischen Kohäsionsmechanismen, die Ansatzpunkte für eine Pluralisierung von Sinn eröffnen, durch Anwendung eines methodisch kontrollierten Verfahrens hermeneutischer Auslegung und definitorischen Anspruchs auf die eine >richtiges Lesart zu verpflichten und in einem ganz bestimmten Sinn zu vereindeutigen. Die lateinische Sprache als Mittel gelehrt-wissenschaftlicher Erörterung speist

97 Dazu Flasch: Meister Eckhart (s. Anm. 89), S. 282.

98 Vgl. grundlegend Köbele: Emphasis, überswanc, underscheit (s. Anm. 93), S. 969-1002.

99 Ebd., S. 988 u. 991.

100 Ebd., S. 991.

101 Köbele: Vom `Schrumpfen` der Rede auf dem Weg zu Gott (s. Anm. 40), S. 126.

102 Haug: Meister Eckhart und das Granum sinapis (s. Anm. 44), S. 84.

103 Vgl. Matthias Hammerle: Das Bild der Juden im Johannes-Kommentar des Thomas von Aquin. Ein Beitrag zu Bibelhermeneutik und Wissenschaftsgeschichte im 13. Jahrhundert. Stuttgart 2011, S. 65-72. Zur Typisierung scholastischer Vermittlungsmethoden vgl. Carmen Cardelle de Hartmann: Lateinische Dialoge 1200-1400. Literaturhistorische Studien und Repertorium. Leiden 2007. 
den deutschen Text in einen terminologisch eindeutig differenzierten Diskurs scholastischer »Problementscheidungsverfahren « ein. ${ }^{104}$

Dieser Gestus des Kommentars, der sich grundlegend von dem im Rahmen der >klassischen lectio etwa antiker Autoren praktizierten Verfahren unterscheidet, ${ }^{105}$ gewinnt seine historische Signifikanz im Kontext der Inkriminierung der zentralen Lehrsätze Meister Eckharts, zeichnet sich doch das Granum sinapis in konzeptueller Hinsicht durch grundlegende Übereinstimmungen mit den häretisierten >Irrlehren aus. ${ }^{106}$ Ziel ist eine dogmatische >Korrektur der semantischen Vielschichtigkeit des deutschen Textes und seines spekulativen Sinnpotentials, die das Gedicht einem stärker orthodox ausgerichteten Modell annähert. Das geschieht auf der Diskursebene durch eine enge Rückbindung der Aussagen an zentrale Autoritäten der christlich-theologischen Tradition. Schon der allegorische Titel, ${ }^{107}$ mit dem der Kommentar den deutschen Text versieht (granum sinapis, parvum in substantia, magnum in virtute 2,1; >Das Senfkorn, klein in der `Substanz`, groß in der Wirkkraft $\triangleleft),{ }^{108}$ rekurriert programmatisch auf ein biblisches Gleichnis, das ein Vergleichsmoment mit dem regnum Dei (Mc 4,30) fokussiert:

sicut granum sinapis quod cum seminatum fuerit in terra minus est omnibus seminibus quae sunt in terra et cum seminatum fuerit ascendit et fit maius omnibus holeribus et facit ramos magnos ita ut possint sub umbra eius aves caeli habitare.

(Mc 4,31f.)

>Wie das Senfkorn, das, wenn es in die Erde gesät wird, kleiner ist als alle Samen, die es auf der Erde gibt; und nachdem es gesät ist, wächst es und wird größer als alle Gewächse und entwickelt so seine großen Zweige, dass die Vögel des Himmels unter seinem Schatten wohnen können.८

104 Köbele: Vom `Schrumpfen` der Rede auf dem Weg zu Gott (s. Anm. 40), S. 127.

105 Dabei gehört die Erklärung einzelner Wörter und Formulierungen im Kontext der jeweils ausgelegten Stellen zu den Basisinstrumenten der Arbeit am Text. Vgl. einschlägig Henkel: Deutsche Übersetzungen lateinischer Schultexte (s. Anm. 37).

106 Zahlreiche im Granum sinapis enthaltene Motive und Metaphern weisen "unmissverständlich auf die Lehre Eckharts«. Haas: Sermo Mysticus (s. Anm. 52), S. 315. Zu dieser Frage oben, S. 189. Die inkriminierten `Irrlehren « diskutiert Flasch: Meister Eckhart (s. Anm. 89), S. $283-296$.

107 Die Überschrift, die den Text des Kommentars im Faszikel der Basler Handschrift eröffnet (Granum sinapis de divinitate pulcherrima in vulgari), stammt indes nicht, wie Haug angenommen hatte (Meister Eckhart und das Granum sinapis [s. Anm. 44], S. 74) vom Kommentator selbst, sondern ist nachträglich vom Bibliothekar der Basler Kartause eingetragen worden. Vgl. Bindschedler: Der lateinische Kommentar zum Granum sinapis (s. Anm. 52), S. 165.

108 Lateinischer Text und Übersetzung im Folgenden nach Bindschedler: Der lateinische Kommentar zum Granum sinapis (s. Anm. 52). 
Das Christuswort dient dem Kommentator dazu, den deutschen Text über das »dialektische Verhältnis von minimaler Gestalt und maximaler Auswirkung « ${ }^{109}$ als göttlich legitimiertes >Heilmittel gegen die Laster` (remedium vitiorum 2,2) zu inszenieren, das >frommen Seelen` (devotis mentibus 2,2) den Weg zum Reich Gottes weisen soll. Mit dieser didaktischen Funktionalisierung des Textes korrespondiert die in der Einleitung vorgenommene Stilisierung als göttlich inspiriert, die auch dem Psalmvers zugrunde liegt, mit dem der Kommentar einsetzt: abissus abissum invocat in voce cataractarum tuarum (1,1; Ps 41,8; >Der Abgrund ruft dem Abgrund mit der Stimme Deiner Wasserfluten`). Nicht die Tiefe (profunditas 1,1) des Textes im eigentlichen Sinne ist es, die eine gelehrt-kommentierende expositio erfordert, sondern die Tiefe des sermo divinus (1,1). Damit weist der Kommentar dem deutschen Gedicht einen geradezu sakralen Stellenwert zu, dem auf der hermeneutischen Ebene - so die Auslegung des zweiten Teils des Psalmzitats (in voce cataractarum tuarum) - als Gewährsmänner die viri divini bzw. caelestes $(1,2)$ entsprechen. Das zielt einerseits auf die im Prozess der Auslegung beigebrachten auctoritates, ${ }^{110}$ die den Anschluss an die biblische sowie patristische Tradition markieren und in diesem Sinne als > Wasserfluten (caractae) den ostia caeli $(1,4)$ verglichen werden, durch die ihnen der Himmel das Geheimnis der individuae trinitatis $(1,4)$ erschlossen habe. Andererseits reiht sich das Subjekt des Kommentars selbst im Modus der expositio göttlich fundierter Rede implizit in diese illustre Reihe ein. ${ }^{111}$ Damit wird eine Gleichrangigkeit von Text und Kommentar modelliert: Wie das Senfkorn entwickelt das in höchster Komprimierung gefasste Sinnpotential des volkssprachigen Gedichts erst durch die Vermittlungsleistung des Kommentars seine volle Wirkkraft. Das ist nicht nur im Sinne einer theologischen Tiefendimension zu verstehen, sondern durchaus auch als Teil einer Legitimationstopik, die den im epilogartigen Gebetsteil des Kommentars als hymnus divinus (81) bezeichneten deutschen Text dem >korrekten`, weil biblisch-theologisch grundierten Verständnis zuführt.

Die Vereindeutigung des mystischen Abstraktionsprozesses vollzieht sich im lateinischen Kommentar sowohl auf der Ebene der terminologischen als auch argumentativen Festlegung. So diskutiert er zum Beispiel in Bezug auf die erste Strophe des deutschen Gedichts ausführlich die auf Io 1,1 rekurrierende, gleichwohl heikle Lesart >istı: In dem begin / [...] / ist ie daz wort (1,1-3). Das

109 Haas: Sermo Mysticus (s. Anm. 52), S. 307.

$110 \mathrm{Zu}$ den Quellentexten des Kommentars (Dionysius Areopagita, Scotus Eriugena, Johannes Sarazenus, Thomas von Aquin) vgl. Haas: Sermo Mysticus (s. Anm. 52), S. 306.

111 Diesen Prozess analysiert Haug: Der Kommentar und sein Subjekt (s. Anm. 27), S. 426-445. 
Abwägen unterschiedlicher Pro- und Contra-Argumente ${ }^{112}$ dient dem Zweck, den Wahrheitsgehalt des vorliegenden tempus praesens zu plausibilisieren und auf diese Weise den Vorwurf einer >Verfälschung ` des tempus imperfectum (erat) in der zugrunde liegenden Bibelstelle zu entkräften. ${ }^{113}$ Die Rechtfertigung legt sich auf das Präsens fest, »da es dem Begriff der Ewigkeit am nächsten komme« (quia ad rationem arternitatis maxime competit praesens tempus 9,3). ${ }^{114}$ Analog verfährt der Kommentar auch an anderen Stellen, besonders dort, wo die volkssprachigen Formulierungen mehrdeutig zu werden drohen, so z. B. bei emphatischen Ausrufen (ô rîcher hort I,4). Hier bemüht sich der Kommentator um eine biblische Fundierung des Wortlauts (vgl. 13,1f.), um eine größtmögliche Verbindlichkeit der Sinnzuschreibung zu erreichen. Ähnliches lässt sich etwa auch im Hinblick auf den Umgang mit den charakteristischen Paradoxien des deutschen Gedichts beobachten: Das Bild des weglosen Weges (vgl. oben, S. 188) verliert durch die Überführung in ein Vergleichsmoment (tamquam) seine metaphorische Qualität; es wird in einer räumlichen und zugleich auch dogmatischen Perspektive differenziert, indem ein sunten erweitert (semita subiecta tamquam inter ea, quae sunt et quae non sunt, duce gratia 69,3). ${ }^{115}$ In einer gleichgerichteten Tendenz wird auch die »dogmatisch brisante Unio der Seele mit Gott [...] ausdrücklich in eine eschatologische Zukunft ausgelagert (>quod solum in futura vita possibile est‘, 75,2 [...])«. ${ }^{116}$ Damit führt der Kommentar mit den Mitteln der dialektisch argumentierenden Quaestio, die den Gesetzen der Logik folgt, aus der im Text bewusst kalkulierten Paradoxie, die ein Vernunftdenken gerade hinter sich $\mathrm{zu}$ lassen intendiert, heraus und repräsentiert eine »Orthodoxie-nähere Position«, die das »traditionelle Teilhabe- und Ähnlichkeitsmodell weit nach vorn [rückt] «. ${ }^{117}$

Was die Frage nach einem funktionalen Aspekt der Koppelung des deutschen Gedichts mit dem lateinischen Kommentar betrifft, so legen die bisher diskutierten Befunde folgende Antwort nahe: Der Kommentar ist Garant für die

112 Eingehend dargestellt bei Köbele: Vom `Schrumpfen` der Rede auf dem Weg zu Gott (s. Anm. 40), S. 127.

113 Zur Diskussion der beiden Lesarten in der Forschung siehe Anm. 64.

114 Köbele: Vom `Schrumpfen der Rede auf dem Weg zu Gott (s. Anm. 40), S. 127. Die Lesart ist wird bezeichnenderweise in der restlichen Überlieferung durch das biblisch abgesicherte Präteritum ersetzt. Dazu Ruh: Textkritik zum Mystikerlied Granum sinapis (s. Anm. 41), S. 85 f.: »Die Schreiber entschieden sich für die `Johannes -Lesart.«.

$115 \mathrm{Zu}$ diesem Aspekt vgl. Köbele: Vom `Schrumpfen` der Rede auf dem Weg zu Gott (s. Anm. 40), S. 129.

116 Ebd., S. 130.

117 Ebd., S. 132. 
Dignität des Textes wie zugleich »Indiz seiner besonderen Wertschätzung « ${ }^{118}$ _ dies aber in einem ganz spezifischen historischen Kontext: Er kann als Reflex der Inkriminierung der von den orthodoxen Konventionen abweichenden Thesen Eckharts gelten, ${ }^{119}$ in deren Zuge offenbar auch das spekulative, zumal in der Volkssprache verfasste mystische Gedicht gewiss risikobehaftet erschien. ${ }^{120}$ Die >dogmatische Korrektur`, die der lateinische Kommentar vornimmt, korrespondiert mit der Vereindeutigung von Eckharts Thesen durch die Zensoren mittels »Häretisierung [...] qua Auflistung «. ${ }^{121}$ Darin liegt die eigentliche Leistung des lateinischen Kommentars: Es geht nicht um einen Akt ১bloßer« Verständnissicherung des zugrundeliegenden deutschen Textes, sondern um eine auf Autoritäten gestützte Legitimierung und Festlegung, für die der Quaestio-Kommentar das geeignete (wissenschaftliche) Instrument bereitstellt. Zumal er den lyrisch-poetischen, tendentiell sangbaren deutschen Text mit Hilfe einer scholastischen Auslegeordnung in ein terminologisch abgesichertes Modell und damit zu einem ausgesprochenen >Lesetext transformiert. ${ }^{122}$ Nur in diesem Sinne >brauchte das Granum sinapis offenbar einen Kommentar.

Mit diesen Beobachtungen ist die Diskussion der Verfasserfrage tangiert. Bereits Kurt Ruh hatte die sist<-Lesart der ersten Strophe als »spezifische Eckhart-Aussage« identifiziert, die er als »Identitätsbrücke vom Kommentar zu Eckhart « interpretierte. ${ }^{123}$ Einen gewichtigen Anhaltspunkt bietet in jedem Fall die Überlieferung:

118 Ebd.

119 Die inkriminierten »Sätze [siedeln] die gottmenschliche Unio in einem Bereich jenseits von Gnadenvermittlung und heilsgeschichtlichem Verlauf an[ ], in einem gegenwärtigen `nû‘, in jener Abgeschiedenheit und weglosen Wüste, von der durchaus auch das Granum sinapis-Lied spricht.« Köbele: Vom `Schrumpfen ‘ der Rede auf dem Weg zu Gott (s. Anm. 40), S. 131. Vgl. dazu Burkhard Hasebrink: Die Anthropologie der Abgeschiedenheit. Urbane Ortlosigkeit bei Meister Eckhart. In: Freimut Löser, Dietmar Mieth (Hg.): Meister Eckhart im Original. Stuttgart 2013, S. 139-154.

120 So auch Haug: Meister Eckhart und das Granum sinapis (s. Anm. 44), S. 84: Der Kommentar »hätte dann das Ziel gehabt, das Gedicht und die volkssprachige mystische Theologie, für die es stand, dadurch in Schutz zu nehmen, daß man jeden Gedanken und jedes Bild durch Autoritäten absicherte.«.

121 Köbele: Vom `Schrumpfen der Rede auf dem Weg zu Gott (s. Anm. 40), S. 1001.

122 Zum `Gefahrenpotential« mystischer Poesie in der Volkssprache vgl. Haug: Meister Eckhart und das Granum sinapis (s. Anm. 44), S. 84: »Die Übernahme theologisch-gelehrter Mystik in die Volkssprache war an sich schon ein Wagnis, vor allem, wenn es nicht einmal um eine Predigt ging - und das war bekanntlich schon risikobeladen -, sondern um Poesie.«.

123 Ruh: Meister Eckhart. Theologe, Prediger, Mystiker (s. Anm. 41), S. 50. Ein wichtiges Argument bildet der Johannes-Kommentar als »exegetisches Hauptwerk Eckharts« (ebd.), worin die entsprechende Passage (Io 1,1) mit ähnlichen Implikationen wie im Granum sinapis diskutiert wird. 
Dieser Befund, der Kommentar als früheste Existenzform des Gedichts in der Überlieferung, läßt sich zwanglos, wenn nicht durch Personengleichheit, so doch nur durch die Personenverbindung von Dichter und Kommentator erklären. ${ }^{124}$

Es ist fraglich, was mit der von der jüngeren Forschung favorisierten unspezifischen Annahme eines anonymen Verfassers, der die theologisch-mystische Sinndimension des deutschen Textes sehr genau kennen musste und an der lateinischen Gelehrtenkultur der Zeit partizipierte, in diesem Kontext eigentlich gewonnen ist. Daher wäre vielleicht neu zu überlegen, ob die Zuschreibung an Eckhart selbst, wie Ruh sie im Sinn hatte, - gerade vor dem Hintergrund der evidenten sprachlichen und konzeptuellen Übereinstimmungen, aber besonders der historischen Konstellation - nicht doch bedenkenswert wäre. ${ }^{125}$

\section{Sozialhistorische Perspektiven auf die Überlieferung des Granum sinapis}

Die Notwendigkeit einer sozialhistorischen Rückbindung des Tradierten tritt in der Überlieferung des Granum sinapis zutage, die zwei distinkte Filiationen ausbildet: ${ }^{126}$ Neben vier Handschriften, die den Text mit dem lateinischen Kommentar enthalten, ist das deutsche Gedicht in drei Handschriften des 15. Jahrhunderts mit einem volkssprachigen Paratext verbunden, ${ }^{127}$ der weniger einen $>$ Kommentar im eigentlichen Sinne bietet als vielmehr »freie Meditationen « von gebetsartigem Charakter, was auch der handschriftlich überlieferte Titel impliziert: ein andechtige betrachtunge. ${ }^{128}$ Bemerkenswert ist, dass der deutsche Paratext - das dokumentiert

124 Ebd., S. 50.

125 Dass Eckharts Name bzw. Referenzen auf seine Schriften im Kommentar nicht explizit genannt werden, wäre im Hinblick auf die historische Konstellation nur als folgerichtig zu betrachten. Vgl. Ruh: Granum sinapis (s. Anm. 41), Sp. 222f.: »Was Meister Eckhart betrifft, so scheint ihn der Kommentator zu kennen, zitiert ihn indes nicht«.

126 Im Folgenden ist nur die Verzweigung der Überlieferung im Hinblick auf die Kombination mit unterschiedlichen Paratexten relevant, nicht die spezifischen Befunde zum deutschen Text. Vgl. Ruh: Textkritik zum Mystikerlied Granum sinapis (s. Anm. 41), S. 78 f.; Päsler: Ein neuer Textzeuge des Granum sinapis (s. Anm. 46), S. 61f.

127 Eine Übersicht bietet Theben: Die mystische Lyrik des 14. und 15. Jahrhunderts (s. Anm. 48), S. $187 \mathrm{f}$.

128 Edition des deutschen Textes bei Ernst Hellgardt: Ein andechtige betrachtunge. Der deutsche `Kommentar`zum Granum sinapis. In: Impulse und Resonanzen. Tübinger mediävistische Beiträge zum 80. Geburtstag von Walter Haug. Hg. von Gisela Vollmann-Profe, Walter Haug. Tübingen 2007, S. 301-322 (Edition S. 304-318); dort auch das Zitat S. 322. 
die handschriftliche Überlieferung - offenbar im süddeutschen Raum entstand, nicht aber auf der Grundlage des ältesten Basler Manuskripts; denn die beiden Filiationen haben sich offenbar schon früh unabhängig voneinander entwickelt. ${ }^{129}$ Es müssen also Transferprozesse im 14. Jahrhundert angesetzt werden, die mit dem Wechsel des regionalen Umfelds auch Veränderungen der Gebrauchssituation des Textes zeitigen. ${ }^{130}$ Beide Filiationen lassen sich vor dem Hintergrund der Überlieferungsorte an unterschiedliche sozialhistorisch differenzierte Kontexte rückbinden. Ausgehend von der Annahme, dass der Kommentar der Verhandlung und schriftlichen Fixierung von gruppenspezifisch `systemrelevantem Selbstvergewisserung eines Kollektivs dient, soll im Folgenden eine überlieferungsgeschichtlich grundierte, sozialhistorisch perspektivierte Interpretation von >Text । und `Kontext` vorgeschlagen werden.

Es fällt auf, dass diejenigen Handschriften, die das Granum sinapis als Teil des lateinischen Kommentars überliefern, soweit die mittelalterlichen Besitzverhältnisse rekonstruierbar sind, sich institutionell männlichen Ordensgemeinschaften zuordnen lassen. ${ }^{131}$ Diese Provenienzen weisen in die Sphäre eines primär gelehrt-wissenschaftlich orientierten Rezeptionsinteresses, bei dem offenbar nicht eine performative Realisierung des Granum sinapis als >geistliches Lied`, sondern eher eine nach scholastischen Kategorien verfahrende, auf hohem Abstraktionsniveau geführte theologische Reflexion im Vordergrund gestanden hat. Diesen Aspekt dokumentiert z. B. der von Päsler beschriebene, der Deutschordensbibliothek des samländischen Domkapitels zugeordnete Textzeuge T, der das Granum sinapis in einem Überlieferungskontext mit lateinischen theologischen Werken präsentiert (z. B. Petrus Comestor, Petrus de Riga u. a.) und dieses an eine Kurzfassung des lateinischen Kommentars anbindet ${ }^{132}$ - es bestand wohl

129 Das hat Ruh auf der Grundlage von Leitvarianten des deutschen Gedichts herausgearbeitet und in einem Stemma festgehalten. Vgl. Ruh: Textkritik zum Mystikerlied Granum sinapis (s. Anm. 41), 88.

130 Dass mit solchen Transferprozessen im Zusammenhang mit mystischen Liedern grundsätzlich zu rechnen ist, argumentiert Theben: Die mystische Lyrik des 14. und 15. Jahrhunderts (s. Anm. 48), S. 189.

131 Basel, Universitätsbibliothek, Cod. B IX 24; Thorún, Universitätsbibliothek, Rps. 75/III; Wien, Österreichische Nationalbibliothek, Cod. 4868; Zeitz, Bücherei der St. Michaeliskirche, Nr. 347 (verschollen). Vgl. Theben: Die mystische Lyrik des 14. und 15. Jahrhunderts (s. Anm. 48), S. 187 f. Die älteste Basler Handschrift ist ab 1401 in der Basler Kartause nachweisbar. Der von Päsler (Ein neuer Textzeuge des Granum sinapis [s. Anm. 46], S. 58-67) beschriebene Neufund: das Fragment T, dürfte aus dem ostmitteldeutschen Raum ab 1430 in die Deutschordensbibliothek des samländischen Domkapitels gelangt sein.

132 Päsler: Ein neuer Textzeuge des Granum sinapis (s. Anm. 46), S. 60. Dieser Befund ist mit der Zusammenstellung der Texte in der Basler Handschrift vergleichbar. Vgl. Burckhardt, 
das Bedürfnis, die Kernpunkte der diffizilen scholastischen Diskussion in Form einer pointierten ıSumma zu erfassen.

Daneben erscheint das Granum sinapis überwiegend in Handschriften aus dem Besitz süddeutscher Frauenkonvente (v.a. in Straßburg und Nürnberg) mit einem deutschen Paratext kombiniert, ${ }^{133}$ der anstelle der scholastischen Auslegeordnung einen meditativen Gestus mit dem Ziel geistiger aedificatio aufweist. ${ }^{134}$ Diese andechtige betrachtunge ${ }^{135}$ bietet einen vom lateinischen Kommentar völlig unabhängigen Zugriff auf das deutsche Gedicht. Signifikant ist der eigenständige Titel, der das lateinische Lehnwort conclusion mit der deutschen Entsprechung slosrede versieht: Dis sint acht conclusion und slos rede von der heiligen drivaltikeit als sie genomen sint us den worten Sancti Dyonisii in dem bůche de mistica theologia (S. 304). Nach Hellgardt weist die verwendete Terminologie auf einen »(vulgär?)theologisch gelehrten Hintergrund «, ${ }^{136}$ auf dessen Basis sich die betrachtunge im Kontext eines Sprach- und Wissenstransfers aus dem gelehrt-lateinischen Milieu in die volkssprachig dominierte Frömmigkeitspraxis gerade süddeutscher Frauenkonvente verorten lässt, ein Prozess, der auch sonst vielfach zu beobachten ist. ${ }^{137}$ Der deutsche Paratext selbst hat, auch wenn die mediale Präsentation an ein kommentarartiges Verfahren erinnert, bei dem ein oder mehrere Verse des Primärtextes mit erklärenden Notaten versehen sind, »nach Inhalt und Stil über weite Strecken hin nicht den Charakter einer Erläuterung oder wissenschaftlichen Diskussion «. ${ }^{138}$ Vielmehr zeichnet er sich an zahlreichen Stellen durch einen ausgesprochenen Ge-

Meyer: Die mittelalterlichen Handschriften der Universitätsbibliothek Basel (s. Anm. 47), S. 336-348.

133 Karlsruhe, Badische Landesbibliothek, Cod. K 1222; Berlin, Staatsbibliothek Preußischer Kulturbesitz, Ms. germ. quart. 192; Nürnberg, Stadtbibliothek, Cent. VI, 54. Vgl. Theben: Die mystische Lyrik des 14. und 15. Jahrhunderts (s. Anm. 48), S. 187.

134 Dazu Susanne Köbele: `Erbauung - und darüber hinaus. Spannungen im volkssprachlich-lateinischen Spätmittelalter. Mit Überlegungen zu Gertruds von Helfta Exercitia spiritualia. In: PBB 137 (2015), S. 420-445; Susanne Köbele: aedificatio. Erbauungssemantiken und Erbauungsästhetiken im Mittelalter. Versuch einer historischen Modellierung. In: Susanne Köbele, Claudio Notz (Hg.): Die Versuchung der schönen Form. Spannungen in >Erbauungs «-Konzepten des Mittelalters. Göttingen 2019, S. 9-37.

135 Im Folgenden zitiert nach Hellgardt: Ein andechtige betrachtunge (s. Anm. 128), S. 304318.

136 Ebd., S. 321.

137 Die »Überlieferung mystischer Lyrik im 14. Jahrhundert [hat] im deutschsprachigen Südwesten einen ersten Höhepunkt erlebt und sich von dort auch in andere Gebiete bewegt«. Theben: Die mystische Lyrik des 14. und 15. Jahrhunderts (s. Anm. 48), S. 111. Zu diesem Phänomen vgl. auch Barbara Fleith, René Wetzel (Hg.): Kulturtopographie des deutschsprachigen Südwestens im späteren Mittelalter. Studien und Texte. Berlin 2009.

138 Hellgardt: Ein andechtige betrachtunge (s. Anm. 128), S. 322. 
betsgestus aus, der den deutschen Text als Medium einer andächtigen Übung präsentiert, »die mit den sprachlichen Mitteln des Bitt-, Lob- und Dankgebetes formuliert « ist. ${ }^{139}$ Dies dokumentieren z. B. die Ausführungen zum bereits besprochenen Zitat nach Io 1,1 (allerdings ohne die ıspektakuläre` präsentische Lesart):

\section{Hoch uber sinn}

\section{was ye das wort}

O herre $\cdot$ so du der bist · der do allein gibt verstentnisse dem glöben · gib auch mir als vil als du bekennest - das es mir nucze ist · das ich dich verstan můge. $O$ ewige warheit - wie gar verre bist du von miner angesicht · so ich doch alle zit · gegenwurtig ston vor dinen ögen! Du bist an allen steten gegenbürtig - gantz und gar · und ich sich dich doch nicht. Ich wirt alle zit in dir beweget · ich bin in dir · ich leb in dir · und mag doch niht zu dir komen · noch gan. Dar umb min sele · erwache nu von dinem slaffe · und richt uf alle din verstentnisse! Vach an ze gedencken als vil du macht · was · und wie · das gůt sig · das got selber ist! O wie sůsse · wie begirlich · wie gros · wie ungemessen · ist das ewige gůt! [...] O ungemesne güte · die do alle verstentnisse der herczen ubertriffet · erluchte nu min ögen · das ich nimer entslaffe des ewigen todes [...] $O$ liber herre · ich bit dich · das öch din erbermde küme nu uber mich [...] Min herre und min got · los och nu flissen · din gnad in mich · als sie us gat von dir! [...]. Amen.

(S. 307, Z. 13-28)

Die betrachtunge arbeitet mit Anrufen, Exklamationen und Anredewechseln (Gott, Seele), die keiner strikten scholastischen Logik folgen, sondern die Rezipientinnen durch die sprachliche Intensivierung im Register liturgiehaften Sprechens ${ }^{140}$ in einen Zustand geistiger Andacht versetzen wollen, das mit der Bitte um Erkenntnisfähigkeit die grundsätzliche Erlösungsbedürftigkeit des Menschen gegenüber der Gefahr des ıewigen Todes` fokussiert. Dabei wächst die betrachtunge über das deutsche Gedicht hinaus, indem sie allenfalls in loser Assoziation zu den jeweils anzitierten Textpartien steht.

Diese evidente Andersheit des deutschen Paratextes gegenüber dem lateinischen Kommentar dokumentiert eine Loslösung des Granum sinapis von seinem ursprünglichen Überlieferungskontext. Mit zunehmendem historischem Abstand erscheint der im Prozesskontext gebotene apologetische Charakter und die diesen tragende scholastische Form der (schriftlichen) wissenschaftlichen Quaestio als obsolet. Damit geht eine Verschiebung des Gebrauchskontextes einer, der nun im Bereich geistiger Meditation »beim Anlaß des gegebenen

139 Ebd.

140 Dazu Hellgardt: Ein andechtige betrachtunge (s. Anm. 128), S. 322: "Dabei erreichen diese Gebetsmeditationen mit ihren reichen Formen liturgiehafter (Symbolum >Quicumque $!$ ) und biblizistischer Salbungsfülle das Niveau einer anspruchsvollen Kunstprosa«. 
Textes « zu situieren ist. ${ }^{141}$ Dass gerade diese Art der volkssprachigen Frömmigkeitspraxis historisch insbesondere im 14. und 15. Jahrhundert im Umfeld süddeutscher Klöster belegt ist, ${ }^{142}$ verweist auf einen Transfer des geistigen und sozialhistorischen Umfelds. Dabei kommt gerade observanten Frauenkonventen eine tragende Rolle als führenden Institutionen im Hinblick auf die Überlieferung mystischer Lyrik zu. ${ }^{143}$ Hauptzentren sind das Gebiet am Oberrhein sowie die Städte Nürnberg und Augsburg ${ }^{144}$ - ein Befund, in den sich auch die Handschriften, die das Granum sinapis mit der betrachtunge tradieren, einordnen lassen. Die meditative Lektüre des Textes als geistige Kontemplationsübung fügt sich in ein historisch fassbares Interesse dieser monastischen Institutionen an »mystischen Texten und mystischem Erleben « als »insbesondere für Frauen geeignete Form der religiösen Aktivität« ein. ${ }^{145}$ Dabei scheint das deutsche Gedicht, so legt es die Überlieferung nahe, wiederum nicht als sangbarer Text existiert zu haben; sein poetisches Potential stellt vielmehr eine Memorierhilfe und eine Art >geistige Gebetsformel bereit, die - angeleitet durch die andechtige betrachtunge - als ein »in stiller Kontemplation nach innen gewendete[r] Gesang « vorzustellen ist,

bei dem der Strophentypus dann nicht als Melodiegerüst fungiert, sondern als formale Stütze auf dem Weg durch die ambivalente Metaphorik und die Paradoxa mystischen Sprechens, die das Granum sinapis von Vers zu Vers generiert. ${ }^{146}$

\section{Konklusion: Der Kommentar als Reflexionsmedium sozialgeschichtlicher Formationen}

Es hat sich gezeigt, dass der Kommentar Einblicke bietet in eine epistemische Ordnung, die die Interessen eines Kollektivs und damit eines historischen Wis-

141 Ebd.

142 Vgl. Theben: Die mystische Lyrik des 14. und 15. Jahrhunderts (s. Anm. 48), S. 112: »Die Überlieferung mystischer Lieder im Kontext observanter Frauenklöster im 14. und 15. Jahrhundert ist mit Sicherheit im Zusammenhang der wachsenden Bedeutung der privaten und außerliturgischen Frömmigkeit zu sehen.«.

$143 »$ Für mystische Lieder erweisen sich dabei observante Frauenklöster als Hauptüberlieferungsorte«. Ebd., S. $64 \mathrm{f}$.

144 Vgl. ebd., S. 111.

145 Ebd., S. 111 u. 112.

146 Steffen: Das Granum sinapis und die Sequenzen Adams von St. Victor (s. Anm. 42), S. 417. 
sensdiskurses reflektiert. Der Funktionalisierung des Granum sinapis durch den lateinischen Kommentar und die deutsche betrachtunge liegen durch die Überlieferung dokumentierte, kontextspezifisch organisierte und insofern sozialgeschichtlich differenzierte Prinzipien zugrunde: Die integrale Einheit aus Text und Kommentar in der ältesten Basler Handschrift semantisiert das deutsche Gedicht als Element einer gelehrt-theologischen Auseinandersetzung apologetischen Charakters, die darauf zielt, die volkssprachigen (im Rahmen des gegen Eckhart geführten Inquisitionsprozesses inkriminierten) Konzepte mit der terminologischen Präzision der lateinischen Diskurssprache zu vereindeutigen. Der Kommentar leistet zweierlei: Er verbirgt, indem er den deutschen Text im wahrsten Sinne des Wortes sinkorporiert‘; zugleich entbirgt er zwar den Sinngehalt des zugrundeliegenden Gedichts, aber dogmatisch `korrigiertı, und überdies in einer Form, die den deutschen Text nicht als kohärente Einheit präsentiert, sondern mittels eines wissenschaftlich-scholastisch abgesicherten autoritativen Rahmens ıgeschützt`, d. h. zugleich legitimiert. Die Überführung des Granum sinapis aus dem gelehrt-lateinischen Milieu in eine volkssprachig orientierte Frömmigkeitspraxis, wie sie die andechtige betrachtunge indiziert, weist in die Observanzbewegung des deutschen Südwestens, in deren Rahmen sich insbesondere Frauenkonvente als bevorzugte Rezeptionsorte mystischer Lyrik herauskristallisieren. ${ }^{147}$ Damit erweist sich der Kommentar als Inbegriff der geistig konzipierten und durch spirituelle Lektüre rezipierbaren Welt und lässt sich als Reflexionsmedium sozialgeschichtlicher Formationen beschreiben. Die vorgeschlagene Lektüre bildet den Versuch, unterschiedliche Parameter hinsichtlich der „Existenzform « ${ }^{148}$ des Granum sinapis (literaturwissenschaftliche Analyse, Überlieferungsbefunde, gesellschaftsgeschichtliche Kontexte) zusammenzudenken. Die gewählte Fokussierung kann dabei helfen, den Blick zu schärfen für eine literatur- und sozialhistorische Differenzierung des Problemzusammenhangs von >Text und >Kontext`.

147 Vgl. Theben: Die mystische Lyrik des 14. und 15. Jahrhunderts (s. Anm. 48), S. 64 f. 148 Ruh: Meister Eckhart. Theologe, Prediger, Mystiker (s. Anm. 41), S. 50. 
